\title{
An experimental study of amniotic lacrimal duct stents in the treatment of perimenopausal female rabbits with dry eye
}

\author{
MINGYANG MA*, QING YUAN*, LEI YE, KANGCHENG LIU, LINHONG YE, YOU-LAN MIN, \\ NAN JIANG, QINGHAI LI, WENQING SHI, XIAOWEI XU, PEIWEN ZHU and YI SHAO \\ Department of Ophthalmology, Clinical Ophthalmology Institute, \\ The First Affiliated Hospital of Nanchang University, Nanchang, Jiangxi 330006, P.R. China
}

Received February 22, 2018; Accepted August 15, 2018

DOI: $10.3892 / \mathrm{mmr} .2018 .9731$

\begin{abstract}
The aim of the present study was to investigate the effects of an amniotic membrane lacrimal stent in the treatment of dry eye syndrome in a perimenopausal rabbit model. In total, 48 healthy female rabbits were randomly divided into four groups (12 rabbits/group): Group A, sham-operated group; group $\mathrm{B}$, negative control group; group $\mathrm{C}$, sham-implantation group; and group D, implantation with amniotic membrane lacrimal stents. A Schirmer I test (SIT), corneal fluorescein staining, optical coherence tomography angiography and corneal confocal microscopy were conducted and the biomechanical properties of the amniotic membrane were measured prior to and 2, 4 and 6 weeks after the operations. There were marked differences in the amount of tear secretion and the SIT following the operation compared with prior to the operation. The amount of tear secretion of group $\mathrm{B}$ and $\mathrm{C}$ was significantly reduced $(\mathrm{F}=8.894 ; \mathrm{P}=0.0017)$. Compared with groups A, B and C, group D demonstrated a significant increase in the amount of tear secretion and a significant reduction in SIT $(\mathrm{P}<0.05)$. However, there was no statistical difference between the tear secretion of the $\mathrm{A}, \mathrm{B}$ and $\mathrm{C}$ groups $(\mathrm{P}>0.05)$. The cornea epithelial of groups A and D was significantly thinner compared with groups B and C. The superior part [superior temporal (ST)5, superior (S)5, superior nasal (SN)5, ST6, S6 and SN6] was significantly thinner compared with the central part of the cornea epithelium. The corneal epithelia of all groups were thin in the center and thick at the edge. At 6 weeks after the operation, group D exhibited a markedly decreased number of anterior stromal luminescent cells,
\end{abstract}

Correspondence to: Professor Yi Shao, Department of Ophthalmology, Clinical Ophthalmology Institute, The First Affiliated Hospital of Nanchang University, 17 Yongwaizheng Street, Nanchang, Jiangxi 330006, P.R. China

E-mail: freebee99@163.com

*Contributed equally

Key words: amniotic membrane lacrimal stent, dry eye, perimenopausal female rabbits compared with groups A, B and C. Furthermore, the bending degree of corneal stromal neural trunks was significantly improved, and the density, branches and curvature of corneal epithelium sub-basal nerves ameliorated to a certain extent $(\mathrm{P}<0.05)$. Amniotic membrane lacrimal stents demonstrated specific therapeutic effects on dry eye in perimenopausal female rabbits.

\section{Introduction}

Dry eye is a multifactorial ocular surface disease, usually caused by insufficient secretion of lipid, mucus and aqua, leading to abnormal quality, quantity and dynamics of the tear, which induces fatigue, pain, dryness and a burning sensation in the eye $(1,2)$. Dry eye may additionally affect visual function and may associate with ocular surface inflammation or increased tear osmotic pressure (3). At present, dry eye has become one of the most common ocular surface diseases. According to the preliminary results of an epidemiological survey, the incidence rate of dry eye is high, reaching 5-35\% around the world (4). The incidence rate of females is higher compared with males; the majority of females are in perimenopause (5), of which the incidence rate of females over 50 is twice as high as that of males. At present, there exist numerous methods to treat dry eye, of which artificial tears and lacrimal puncta occlusion are the primary ones $(6,7)$.

Compared with the materials commonly used in lacrimal puncta occlusion, the amniotic membrane does not have any nerves, blood vessels or lymphatic vessels, and has tough tenacity and low antigenicity (8-10). In addition, it has certain biological functions, including inhibiting conjunctival squamous metaplasia and inflammation with a low degree of foreign body sensation and irritation (11-14). A previous study suggested that the amniotic membrane may reduce the formation of novel blood vessels, inhibit fibrosis and scar hyperplasia (15). The amniotic lacrimal duct stent is a novel and ideal lacrimal duct, which uses supporting material that is fabricated based on the amniotic membrane. Compared with the currently used lacrimal duct stent, the amniotic lacrimal duct stent has lower antigenicity and better tissue compatibility, with no hormone-like side effects or patient discomfort. It additionally possesses a certain biological function, enabling it to retain residual tears and to treat lacrimal duct obstruction (16). 
The author hypothesized that following the implantation of an amniotic lacrimal stent at the lacrimal duct, the dry eye symptom may be alleviated by retaining residual tears (16). The present study aimed to examine the therapeutic effect of amniotic lacrimal stent implantation in perimenopausal female rabbits, which may provide experimental evidence for treating dry eye in females in perimenopause.

\section{Materials and methods}

Materials. Amniotic membrane lacrimal stents were purchased from Jiangxi Ruiji Biological Engineering Technology Co., Ltd. (Nanchang, China). Schirmer I test (SIT) paper was obtained from Bausch + Lomb (Rochester, NY, USA). Polyvinyl chloride filter paper and plastic film were purchased from Shanghai Peninsula Industrial Co., Ltd. (Shanghai, China).

Experimental animals. New Zealand white rabbits were purchased from the Animal Experiment Department of Nanchang University School of Medicine (Nanchang, China). In total, 48 New Zealand white rabbits (age, 3 months; weight, $1.5-2.0 \mathrm{~kg}$ ) were randomly selected (12-12 h alternating light and dark, ambient temperature $20-25^{\circ} \mathrm{C}$, artificial feeding). The 48 selected female rabbits were evaluated by ophthalmoscopy and slit lamp microscopy, and the result demonstrated that there were no abnormalities in the rabbits. The SIT was $\geq 10 \mathrm{~mm} / 5 \mathrm{~min}$. Ethics approval was obtained from the Medical Ethics Committee of The First Affiliated Hospital of Nanchang University (Nanchang, China).

Surgery and grouping. Incision and suture in the skin of the ovary area were conducted in 12 female rabbits (group A, sham operation group). In order to reduce experimental errors caused by surgical operations, the other 36 female rabbits underwent bilateral ovariectomy. The female rabbits were divided into groups B, C and D (12 eyes each; all right eyes). The postoperative group B (negative control group) was not treated and only observed for 6 weeks. On the day of operation, the lacrimal duct stents were implanted into the lacrimal passages of the female rabbits of group $\mathrm{C}$ for $5 \mathrm{sec}$ and subsequently removed (sham-implantation group). This step was conducted to demonstrate that short-term implantation does not serve a role in treatment. Only by implanting the stent into the body for a long period of time, it is able to gradually function and form a better contrast compared with the other groups. The group D rabbits (amniotic lacrimal duct scaffold group) were implanted with lacrimal duct stents for 6 weeks. Subsequent to the completion of all operations for all the groups, SIT, corneal fluorescein (FL) staining, optical coherence tomography angiography (OCTA) and corneal confocal microscope scanning were performed prior to and following implantation on the 14,28 th and 42 nd day. The rabbits were alive prior to conducting the SIT, corneal FL staining, OCTA and corneal confocal microscopy, and measuring the biomechanical properties of amniotic membrane. All of the operations were conducted in the same test environment and by the same operator.

SIT. SIT was performed with $5 \times 35 \mathrm{~mm}$ scale test paper. Subsequent to folding $8 \mathrm{~mm}$, the folded end was placed at one-third of the inferior conjunctiva sac of the female rabbits in each group, and the rest of the test paper was suspended perpendicularly to the skin surface. After $5 \mathrm{~min}$, the wet length of the scale filter paper was recorded. According to the standard (17), the moist test strip was longer compared with the $10 \mathrm{~mm}$ considered normal. All of the operations were conducted in the same test environment and by the same operator.

Corneal FL score examination. In total, one drop of $1 \%$ fluorescein sodium eye drops was applied to the eyes of the female rabbits in each group. Subsequent to blinking, the corneal epithelial staining was observed by using slit lamps, magnification, $x 10$. The score was measured as previously described (18): i) No staining spots on corneal epithelium recorded as zero points; ii) punctate staining and $<30$ points in the corneal epithelium recorded as one point; iii) corneal epithelial visible spot-like staining and $>30$ points, with no diffusion recorded as two points; iv) diffused infiltration of the corneal epithelium staining, with no plaque formation recorded as three points; and v) visible corneal fluorescein plaque recorded as four points.

Confocal microscopy. The confocal microscopy, magnification, $\mathrm{x} 10$. was performed by the same operator. Measurement of corneal epithelial alterations in the eyes of the female rabbits in each group was performed as previously described (19). The rabbit heads were held to ensure that their eyes were straight, and 5 g..$^{-1}$ Alcaine eye drops (Alcon, Fort Worth, TX, USA) were administered. The full thickness of the central cornea was scanned, clear and effective images were saved, and the density of corneal-activated stromal and inflammatory cells was calculated using computer software Image J V1.8.0 (National, Institutes of Health, Bethesda, MD, USA).

OCTA measurement. The OCTA was imaged with the AngioVue OCTA system (Optovue, Inc., Fremont, CA, USA) retinal-imaging mode (AngioRetina mode), and its split-spectrum amplitude-decorrelation angiography algorithm was used for imaging. Scanning parameters were set as follows: i) Light source: $840 \mathrm{~nm}$; ii) beam width: $22 \mu \mathrm{m}$; iii) lateral resolution: $15 \mu \mathrm{m}$; and iv) axial resolution: $5 \mu \mathrm{m}$. All operations were repeated three times. The autofocus function was turned off to measure corneal full thickness and corneal epithelial thickness to create a chronic lateral 304x304 A-scan of 70,000 beats/second and capture subsequent cross-sectional scans (B-scan) to obtain images.

Nerve density $\left(\mathrm{mm} / \mathrm{mm}^{2}\right)$. The confocal was used to observe the nerve fibers. The corneal plexus was observed with a depth of observation of 35-50 $\mu \mathrm{m}$. The length of the subintimal nerve fibers was determined using AUTOCAD 2016 software (Autodesk, Inc., San Rafeal, CA, USA). Each image was obtained according to the actual corneal area of $0.16 \mathrm{~mm}^{2}$ (400x400 $\mu \mathrm{m})$ per frame, and the shape of nerve fibers was outlined (Fig. 1). The total length of the broken line was determined by the characteristics of the broken line. The total length obtained was divided by area $\left(0.16 \mathrm{~mm}^{2}\right)$ to obtain nerve fiber density $\left(\mathrm{mm} / \mathrm{mm}^{2}\right)$. The ACCMetrics software was used to make statistics of the neural quantity and morphological 
Table I. Comparison of each period of tear secretion prior to and following implantation of the amniotic lacrimal ducts (mm).

\begin{tabular}{|c|c|c|c|c|c|c|c|}
\hline \multirow[b]{2}{*}{ Group } & \multirow[b]{2}{*}{$\mathrm{N}$} & \multirow[b]{2}{*}{ Pretreatment } & \multicolumn{3}{|c|}{ Post-treatment, weeks } & \multirow[b]{2}{*}{$F$} & \multirow[b]{2}{*}{$\mathrm{P}$} \\
\hline & & & 2 & 4 & 6 & & \\
\hline A & 12 & $4.49 \pm 1.55$ & $4.31 \pm 1.55^{\mathrm{c}}$ & $4.29 \pm 1.51^{\mathrm{c}}$ & $4.31 \pm 1.49^{c}$ & 0.572 & 0.124 \\
\hline B & 12 & $4.12 \pm 1.49$ & $3.88 \pm 1.52^{\mathrm{c}}$ & $3.52 \pm 1.56^{\mathrm{c}}$ & $3.23 \pm 1.46^{\mathrm{c}}$ & 11.538 & 0.014 \\
\hline $\mathrm{C}$ & 12 & $4.08 \pm 1.56$ & $3.75 \pm 1.57^{c}$ & $3.29 \pm 1.61^{\mathrm{c}}$ & $2.95 \pm 1.61^{\mathrm{c}}$ & 13.437 & 0.009 \\
\hline $\mathrm{D}$ & 12 & $4.15 \pm 1.41$ & $4.86 \pm 1.62^{\mathrm{b}, \mathrm{c}}$ & $5.72 \pm 1.42^{\mathrm{a}-\mathrm{c}}$ & $4.96 \pm 1.58^{\mathrm{c}}$ & 7.643 & 0.032 \\
\hline
\end{tabular}

A, sham operation group; B, negative control group; $\mathrm{C}$, sham-implantation group; $\mathrm{D}$, amniotic lacrimal duct scaffold group. ${ }^{\text {a }} \mathrm{P}<0.05$ vs. group $\mathrm{A}$; ${ }^{\mathrm{b}} \mathrm{P}<0.05$ vs. group $\mathrm{C} ;{ }^{\mathrm{C}} \mathrm{P}<0.05$ vs. pretreatment.

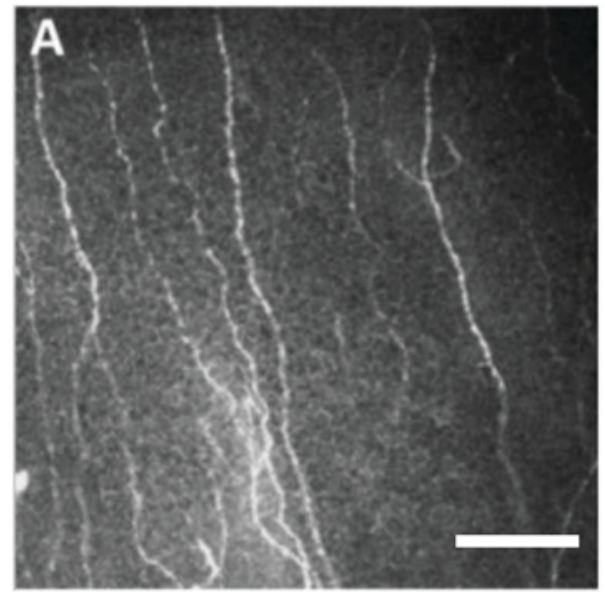

B

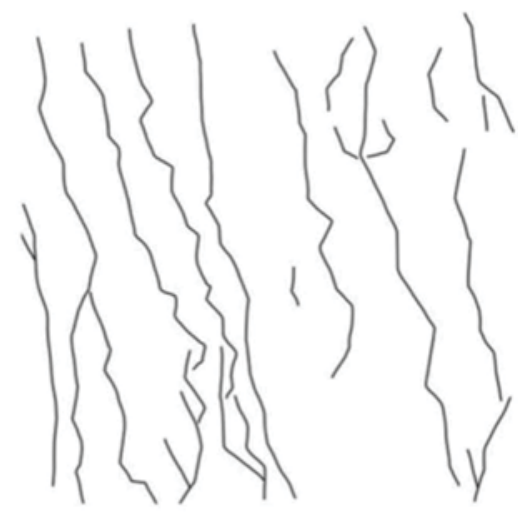

Figure 1. Comparison of nerve fibers in each group. (A) Nerve fibers in confocal microscopy images obtained with computer-aided design software. (B) Polyline analysis of nerve fiber. Scale bar, $100 \mu \mathrm{m}$.

parameters of the selected images. The density of the branch of the cornea nerve: The number of branches of the nerve fibers in the image per square millimeter, in strips $/ \mathrm{mm}^{2}$.

Statistical analysis. GraphPad Prism 4.00 statistical software (GraphPad Software, Inc., La Jolla, CA, USA) was used for the statistical analysis. Data are presented as the mean \pm standard deviation from three independent experiments. The data were analyzed using the $\chi^{2}$ test and the test level was $\alpha=0.05$. Treatment effects prior to and following treatment and group differences were compared by one-way analysis of variance, followed by Dunnett's post hoc test for comparison of multiple sets of data. Student's t-test was used to compare two sets of data. $\mathrm{P}<0.05$ was considered to indicate a statistically significant difference.

\section{Results}

Nerve fibres and polyline analysis. Representative images of nerve fibers and polyline analysis are presented in Fig. 1.

Comparison of SIT result between groups prior to and following implantation. The tear secretion in each time period is presented in Table I. Compared with pretreatment, tear secretion volume in groups $\mathrm{B}, \mathrm{C}$ and $\mathrm{D}$ was significantly altered after 2 and 4 weeks $(\mathrm{F}=11.538 ; \mathrm{P}=0.014)$, and there was no significant difference between group $\mathrm{A}$ and pre-experiment $(\mathrm{F}=0.572 ; \mathrm{P}=0.124)$. Compared with group $\mathrm{A}$, the amount of lacrimal fluid secretion was not increased significantly in group $\mathrm{D}(\mathrm{F}=0.992 ; \mathrm{P}=0.062)$. Compared with group $\mathrm{C}$, the secretion of lacrimal fluid in group $\mathrm{D}$ was significantly increased $(\mathrm{F}=10.543 ; \mathrm{P}=0.009)$. In the fourth week of the experiment, the SIT of the rabbit was normal (16).

FL score comparison between groups prior to and following implantation. The results of corneal FL score in each period are presented in Table II. Compared with prior to intervention, the FL scores of groups B, C and D significantly altered $(\mathrm{F}=8.894 ; \mathrm{P}=0.017)$ and there was no significant difference between group $\mathrm{A}$ and pre-experiment $(\mathrm{F}=0.719 ; \mathrm{P}=0.071)$. Compared with group A, the FL score of group D was not significantly decreased $(\mathrm{F}=0.921 ; \mathrm{P}=0.067)$. The FL score in group $\mathrm{D}$ was significantly decreased compared with group $\mathrm{C}$ $(\mathrm{F}=10.543$; $\mathrm{P}=0.009$; Fig. 2). In the fourth week of the experiment, the FL staining of the rabbits was normal (17).

Thickness of corneal epithelium is measured by OCTA. Taking the right eye as an example, the cornea was divided into 17 regions, of which the central corneal diameter was $2 \mathrm{~mm}$ within the central ring, the middle and outer ring were 5 and $6 \mathrm{~mm}$ away from the corneal center, respectively. The middle ring and the outer ring were equally divided into the 
Table II. Comparison of corneal fluorescein score prior to and following implantation of amniotic lacrimal duct scaffolds.

Following, weeks

\begin{tabular}{lccccccr}
\cline { 3 - 6 } Group & $\mathrm{N}$ & Prior & 2 & 4 & 6 & $F$ & P \\
\hline A & 12 & $3.33 \pm 0.85$ & $3.35 \pm 0.79^{\mathrm{c}}$ & $3.32 \pm 0.78^{\mathrm{c}}$ & $3.34 \pm 0.86^{\mathrm{c}}$ & 0.719 & 0.071 \\
B & 12 & $3.68 \pm 0.69$ & $4.19 \pm 0.96^{\mathrm{c}}$ & $4.94 \pm 1.06^{\mathrm{c}}$ & $5.38 \pm 1.08^{\mathrm{c}}$ & 8.894 & 0.017 \\
C & 12 & $3.58 \pm 0.79$ & $4.18 \pm 0.93^{\mathrm{c}}$ & $4.81 \pm 1.07^{\mathrm{c}}$ & $5.34 \pm 1.11^{\mathrm{c}}$ & 10.153 & 0.015 \\
D & 12 & $3.58 \pm 0.89$ & $3.21 \pm 1.06^{\mathrm{b}, \mathrm{c}}$ & $2.85 \pm 0.62^{\mathrm{a}-\mathrm{c}}$ & $3.24 \pm 0.67^{\mathrm{b}, \mathrm{c}}$ & 15.654 & 0.039
\end{tabular}

A, sham operation group; B, negative control group; $\mathrm{C}$, sham-implantation group; D, amniotic lacrimal duct scaffold group. ${ }^{\mathrm{a}} \mathrm{P}<0.05$ vs. group $\mathrm{A}$; ${ }^{\mathrm{b}} \mathrm{P}<0.05$ vs. group $\mathrm{C} ;{ }^{\mathrm{c}} \mathrm{P}<0.05$ vs. prior to intervention.
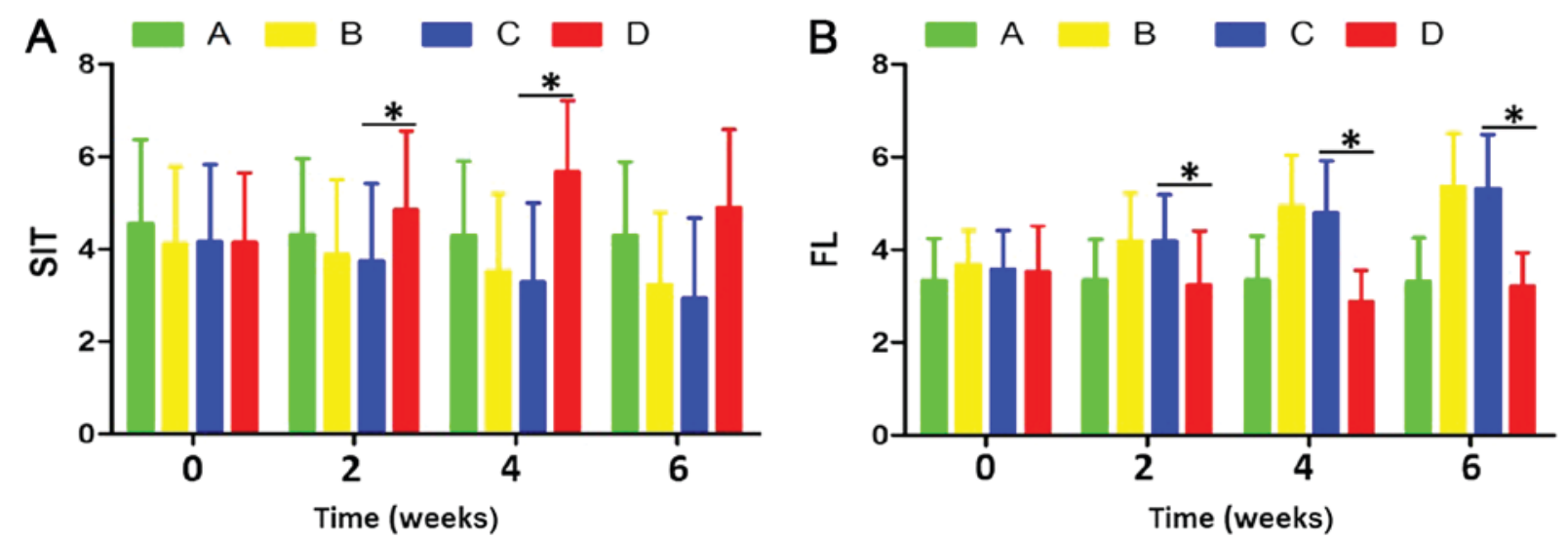

Figure 2. Comparison of tear secretion and FL score in each group. There was a significant difference in (A) tear secretion and (B) SIT following operation. The secretion of tears in group $\mathrm{B}$ and group $\mathrm{C}$ was significantly reduced $(\mathrm{F}=8.894 ; \mathrm{P}=0.0017)$. Compared with groups $\mathrm{A}, \mathrm{B}$ and $\mathrm{C}$, the tear secretion of the $\mathrm{D}$ group increased significantly, and the SIT decreased significantly. "P<0.05. FL, fluorescein; SIT, Schirmer I test; group A, sham-operated; group B, negative control; group C, sham-implantation; group D, implantation with amniotic membrane lacrimal stents.

following areas: Inferior (I), inferior temporal (IT), superior (S), superior nasal (SN), nasal (N), inferior nasal (IN) temporal (T), superior temporal (ST). Corneal epithelial and full corneal thickness was measured in all regions (Fig. 3).

Representative images of the thickness of cornea and corneal epithelium from four individuals in the four groups are presented in Fig. 4A. The thickness of the corneal epithelium in groups A and D was significantly thinner compared with groups $\mathrm{B}$ and $\mathrm{C}(\mathrm{P}<0.05)$. The upper part of the corneal epithelium (ST5, S5, SN5, ST6, S6 and SN6) was significantly thinner compared with the central cornea epithelium $(\mathrm{P}<0.05)$. The corneal thickness of group $\mathrm{D}$ was significantly thinner compared with groups $\mathrm{B}$ and $\mathrm{C}(\mathrm{P}<0.05)$. The corneas of rabbits in groups $\mathrm{A}, \mathrm{B}, \mathrm{C}$ and $\mathrm{D}$ were all thin at the central region and thick at the periphery. In addition, the lower part of the cornea (T5, IT5, IN5, N5, T6 and N6) in each group was significantly thicker compared with the central cornea $(\mathrm{P}<0.05$; Fig. 4B).

Corneal confocal microscopy results. Corneal confocal microscopy was conducted to assess inflammatory cells and activated stromal cells (Fig. 5). In group A, the bright glowing activated stromal cells with a narrow cell boundary were visible (Fig. 5A). Compared with group A, a larger number of bright inflammatory cells was observed in groups $\mathrm{B}$ and $\mathrm{C}$, and the number of activated interstitial cells was significantly increased with more marked deformation (Fig. 5B, C and I; P<0.05). After 6 weeks implantation of amniotic lacrimal duct scaffold, the epithelial basal cell number was slightly increased, compared with group A. However, compared with groups B and C, epithelial basal cells volume in group D was decreased, and the number of bright inflammatory cells was decreased (Fig. 5D). The pictures of activated stromal cells of group A, B, C and D are shown in Fig. 5E-H. The number of activated stromal cells and inflammatory cells in group B were $67 \pm 15$ and $211 \pm 21$ cells $/ \mathrm{mm}^{2}$, respectively after 6 weeks of intervention. The density of activated stromal cells and inflammatory cells in group $C$ were $66 \pm 17$ and $219 \pm 25$ cells $/ \mathrm{mm}^{2}$, respectively. The density of activated stromal cells and inflammatory cells in group D were $29 \pm 8$ and $135 \pm 32$ cells $/ \mathrm{mm}^{2}$, and the difference between group D and groups B and C was statistically significant (both $\mathrm{P}<0.05$ ).

There were only a few luminescent cells in the anterior corneal stroma in group A (Fig. 6A); whereas, a large number of luminescent cells were detected in group B and group C, and the numbers of luminescent cells increased significantly compared with group A (Fig. 6B and C). Following implantation of the amniotic lacrimal duct for 6 weeks, group D demonstrated a slight increase in stromal luminescent compared with group A; however, the numbers were decreased compared with group B and group C (Fig. 6D). 

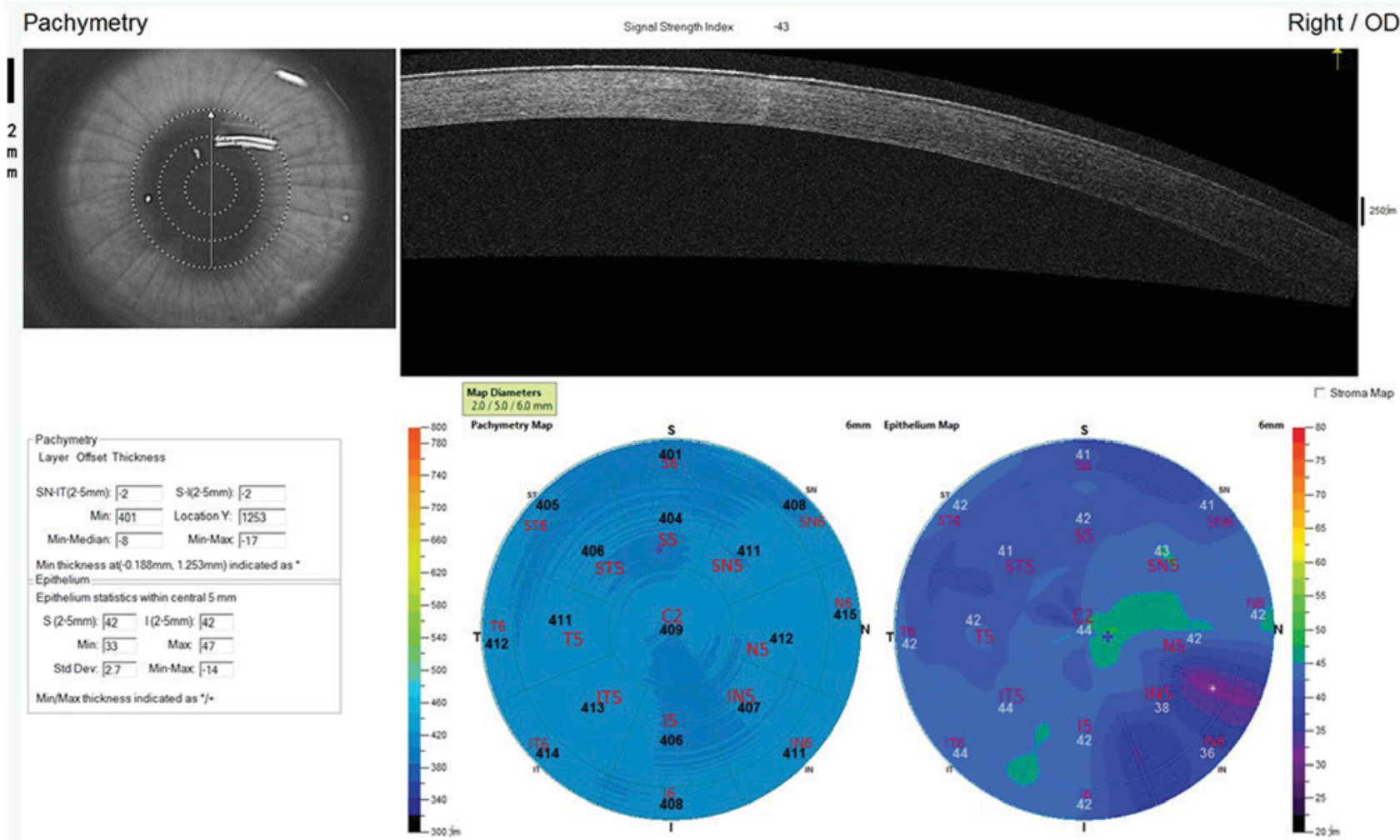

Figure 3. Measurement map of the corneal epithelium and full corneal thickness. The inner cornea was $2 \mathrm{~mm}$ in diameter ring from the center of cornea; the middle and outer ring, were 5 and $6 \mathrm{~mm}$ diameter range from the corneal center, respectively.

Table III. Comparison of nerve under corneal endothelium in different groups.

\begin{tabular}{|c|c|c|c|c|}
\hline Group & $\begin{array}{c}\text { Case } \\
\text { number }\end{array}$ & $\begin{array}{c}\text { Nerve } \\
\text { fiber density, } \\
\mathrm{mm} / \mathrm{mm}^{2}\end{array}$ & $\begin{array}{c}\text { Nerve } \\
\text { fibre branches, } \\
\text { branch number } \\
\text { per image }\end{array}$ & $\begin{array}{c}\text { Curvature } \\
\text { score }\end{array}$ \\
\hline A & 12 & $20.12 \pm 4.21^{\mathrm{b}}$ & $10.95 \pm 2.04^{b}$ & $3.32 \pm 0.67^{\mathrm{b}}$ \\
\hline B & 12 & $15.32 \pm 2.96^{\mathrm{a}}$ & $7.21 \pm 1.87^{\mathrm{a}}$ & $1.91 \pm 0.42^{\mathrm{a}}$ \\
\hline $\mathrm{C}$ & 12 & $16.21 \pm 2.75^{\mathrm{a}}$ & $7.53 \pm 1.92^{\mathrm{a}}$ & $1.82 \pm 0.51^{\mathrm{a}}$ \\
\hline $\mathrm{D}$ & 12 & $19.11 \pm 3.53^{b}$ & $9.81 \pm 1.74^{b}$ & $3.23 \pm 0.78^{b}$ \\
\hline
\end{tabular}

${ }^{\mathrm{a}} \mathrm{P}<0.05$ vs. group $\mathrm{A}$; ${ }^{\mathrm{b}} \mathrm{P}<0.05$ vs. group $\mathrm{C}$. $\mathrm{A}$, sham operation group; $\mathrm{B}$, negative control group; $\mathrm{C}$, sham-implantation group; $\mathrm{D}$, amniotic lacrimal duct scaffold group.

A clear and straight corneal stroma nerve trunk was visible in group A (Fig. 6E). In total, 6 weeks after implantation of amniotic lacrimal duct scaffolds, the nerve trunk of corneal stroma in group D was slightly curved compared with group A; however, improved significantly compared with group B and C (Fig. 6E-H).

Quantitative analysis of nerve prior to and following the amniotic membrane lacrimal duct stent implantation. Prior to amniotic lacrimal duct stent implantation, there was no significant difference in the density, branch or curvature of the corneal subcutaneous nerve in each group in Fig. 6 $(\mathrm{P}>0.05)$. There was no significant difference in the density, branch or curvature of corneal epithelium in group A prior to and following implantation $(\mathrm{P}>0.05)$. The density, branch or curvature of the corneal subcutaneous nerve in groups $\mathrm{B}, \mathrm{C}$ and $\mathrm{D}$ altered prior to and following amniotic lacrimal stent implantation, and the alterations in group B and group C were more marked, the difference was statistically significant $(\mathrm{P}<0.05)$. Following amniotic lacrimal duct stent implantation for 6 weeks, the density, branch or curvature of corneal subcutaneous nerve in group D were significantly improved compared with group $\mathrm{C}(\mathrm{P}<0.05$; Table III).

\section{Discussion}

With aging and the wide application of electronic equipment, dry eye has become one of the most common eye diseases. Causes of dry eye syndrome are very complicated, including ophthalmic surgery, inflammation, immune diseases and metabolic diseases (20). However, due to symptoms, including dryness, foreign body sensation, fatigue, photophobia and a burning sensation in patients (1), clinical treatment must be actively sought (21). Dry eye may be induced if abnormality happens at any of the process of tear formation, distribution, evaporation and removal. Therefore, when designing the causative treatment therapy, the retention and use of limited remaining tear and extrinsic artificial tears are additionally 

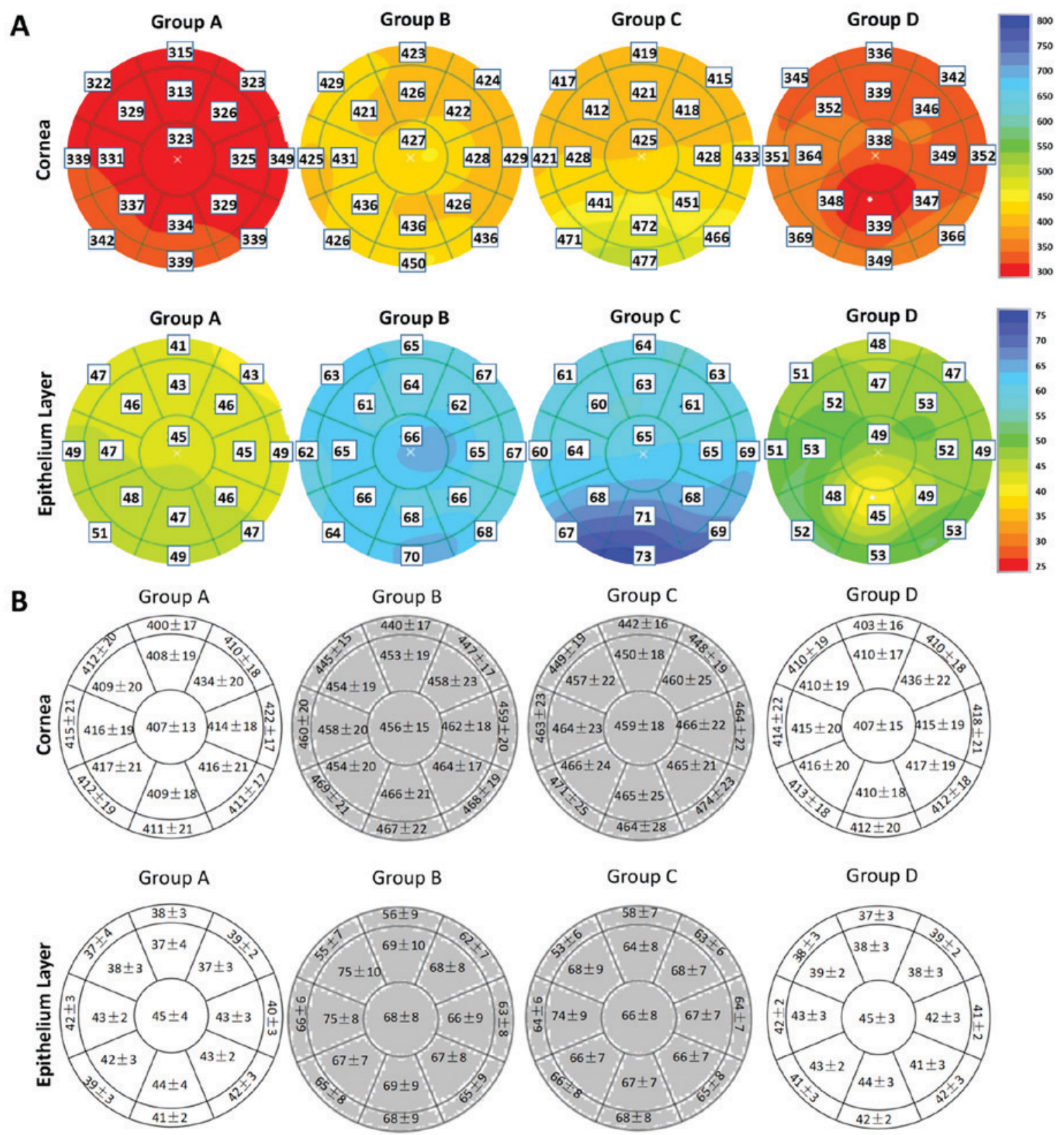

Figure 4. Comparison of the thickness of cornea and corneal epithelium from each group. (A) Images of the thickness of cornea and corneal epithelium from each group. (B) The gray area demonstrated a statistically significant difference compared with the central corneal thickness $(\mathrm{P}<0.05)$. The white area was not statistically significant; whereas, the lower half of the cornea was thicker compared with the central area with statistical significance $(\mathrm{P}<0.05)$. There was a statistically significant difference between groups $\mathrm{A} / \mathrm{D}$ and $\mathrm{B} / \mathrm{C}(\mathrm{P}<0.05)$. The corneal epithelium in group A and group $\mathrm{D}$ was decreased compared with groups B and C. The upper part of corneal epithelium (ST5, S5, SN5, ST6, S6 and SN6) was significantly lower compared with the central part of the corneal epithelium. The center of corneal epithelium was thin and the edge was thick. Group A, sham-operated group; group B, negative control; group C, sham-implantation; group D, implantation with amniotic membrane lacrimal stents.

important factors to consider. However, the additives or preservatives and other ingredients in artificial tears inevitably affect the ocular surface environment and cornea (22). Frequent use of artificial tear will additionally affect the composition of the tear film distribution and accelerate tear evaporation (23). There are a number of effective means of retention and use of tears, of which lacrimal duct embolism is one of the most important treatments (24). Therefore, the present study selected amniotic lacrimal stent treatment to examine the treatment of lacrimal duct embolism.

Amniotic membrane, derived from the trophoblast layer of transparent tissue, containing a large number of bioactive ingredients with relatively soft texture, may nourish the corneal nerve (14). As a lacrimal support, the amniotic membrane is easy to use, safe and non-toxic. It may function as the support itself and may additionally reduce the damage to the eye tissue to a great extent, to improve the current foreign body lacrimal support (25). Furthermore, the anatomy of the amniotic lacrimal support lacrimal duct is similar to the native lacrimal structure, which may adapt to the use of obstruction of the canaliculus to retain residual tears, to avoid the loss of immune proteins and ionic components, and to protect the eye tissue and increase tear film stability, thus serving a therapeutic role in the treatment of dry eye (26). 

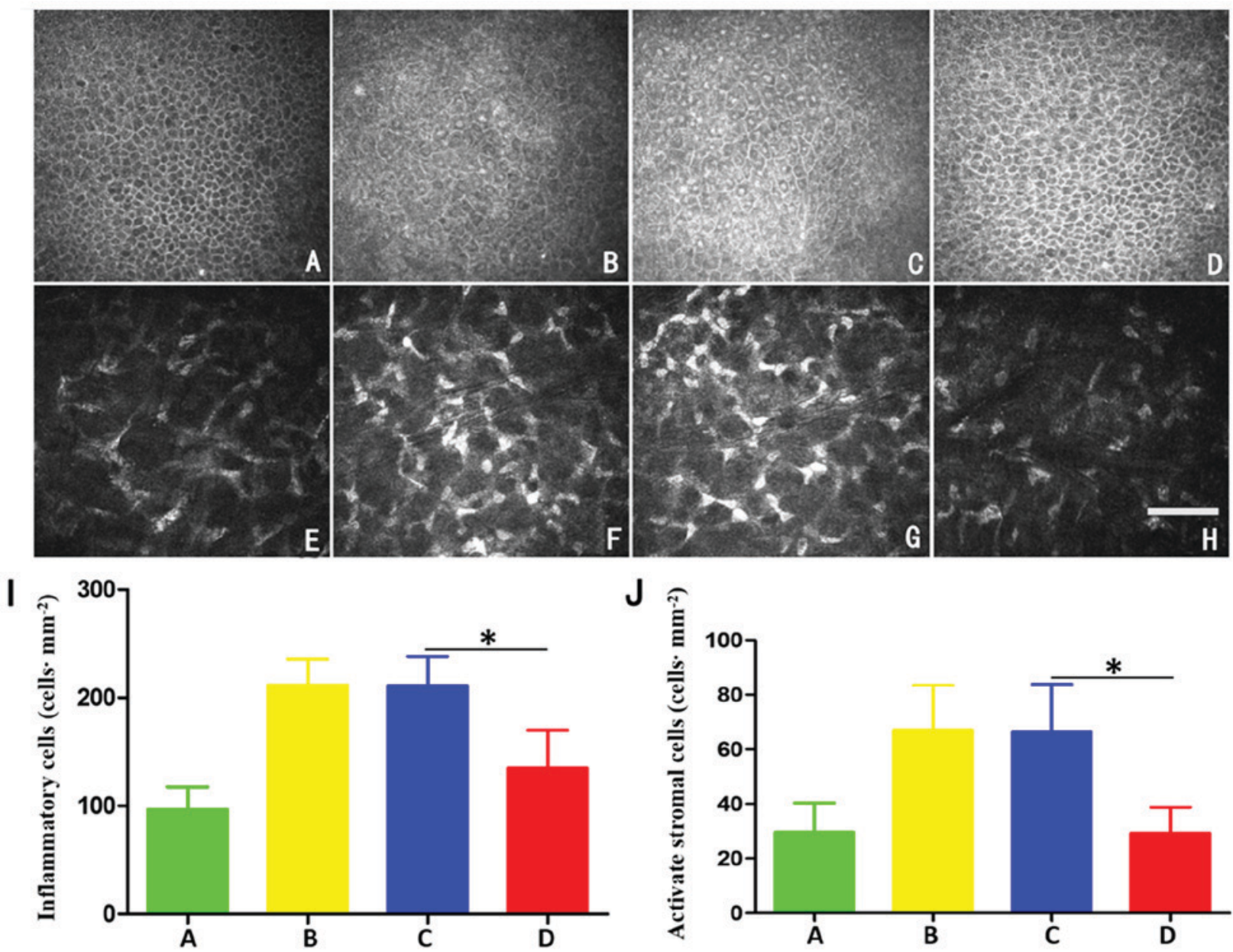

Figure 5. Confocal microscopy images of corneal epithelial cells in each group. (A) Normal control group. (B) Inflammatory cells significantly increase in group B. (C) Inflammatory cells significantly increase in group C. (D) Amniotic lacrimal duct stent group. (E) Bright glowing activated stromal cells with a narrow cell boundary are visible in group A. (F) Activated corneal stroma increases in group B. (G) Activated corneal stromal cells significantly increase in group C. (H) Activated interstitial cells decreased in group D. (I) Comparison of inflammatory cell density in each group. (J) Comparison of activated corneal stromal cell density. Scale bar, $100 \mu \mathrm{m}$. " $\mathrm{P}<0.05$ vs. group D. Group A, sham-operated; group B, negative control; group C, sham-implantation; group D, implantation with amniotic membrane lacrimal stents.
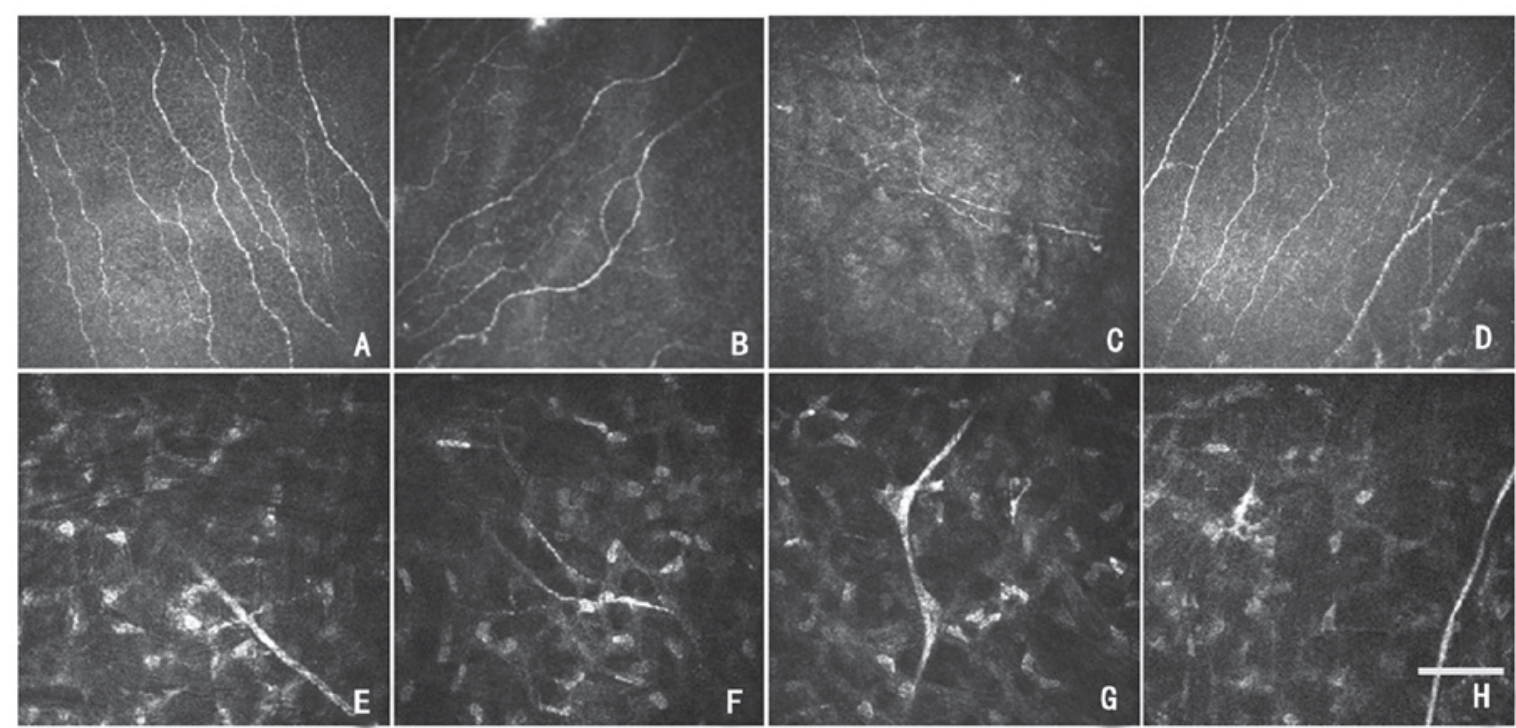

Figure 6. Confocal microscopy images of anterior corneal stromal cells and nerve trunk. (A) Normal control group. (B) Anterior corneal stroma luminescent cells significantly increase in group B. (C) Anterior corneal stroma luminescent cells increase significantly in group C. (D) Anterior corneal stroma luminescent cells significantly decrease in group D. (E) Corneal stroma nerve trunk is clear and straight in group A. (F) Corneal stroma nerve trunk flexed in group B. (G) Corneal stromal nerve trunk flexed in group C. (H) Corneal stromal nerve trunk flexed in group D. Scale bar, $100 \mu \mathrm{m}$. Group A, sham-operated; group B, negative control; group $\mathrm{C}$, sham-implantation; group D, implantation with amniotic membrane lacrimal stents. 
The experimental results demonstrated that compared with groups $\mathrm{B}$ and $\mathrm{C}$, following implantation of the amniotic lacrimal duct stent, SIT and FL values of group D were significantly improved; whereas, the SIT and FL values in groups B and $\mathrm{C}$ deteriorated. The number of epithelial cells in group $\mathrm{D}$ was decreased compared with groups B and C, and the density of inflammatory cells was decreased. The density of corneal epithelial cells in patients with dry eye decreased; whereas, the increase of inflammatory cell density may cause apoptosis of epithelial cells, and epithelial cell apoptosis may lead to the reduction of corneal tear film stability. However, inflammation is not a single factor in dry eye. At the same time, inflammation stimulates epithelial cell edema leading to an increase in the thickness of the corneal epithelium. Multiple mixing mechanisms may lead to squamous epithelial hyperplasia or metaplasia of the corneal epithelium. The implantation of an amniotic lacrimal duct scaffold effectively retains tears, resulting in corneal nutrition, protection and lubrication, and the improvement of dry eye symptoms (27).

As a novel technology with great potential, OCTA may directly observe the range of the lesion and the alteration of the length, caliber, area and other aspects of the corneal epithelium with high sensitivity $(28,29)$. The experimental results demonstrated that following implantation of amniotic lacrimal duct stents, the corneal epithelial hyperplasia of group D was decreased; whereas, the corneal thickness of group B and C increased significantly. Dry eye results in the instability of tear film in female rabbit models, causing corneal damage to a certain degree and increasing inflammatory factors. With time, pro-inflammatory cytokines continue to be secreted, and increase the damage to ocular surface cells. When the corneal microenvironment stability is disrupted, corneal cell proliferation and repair occur (30). Furthermore, the stability of the corneal microenvironment is difficult to recover in dry eye, which hinders the proliferation of corneal cells to a certain extent and affects the corneal tissue repair and healing following injury, leading to the increase of corneal thickness (31). The amniotic lacrimal duct stent implantation retains tears to a certain extent, and maintains the stability of the corneal microenvironment (30). Consequently, corneal damage may be alleviated, and it was hypothesized that amniotic lacrimal support for perimenopausal dry eye in rabbits has good efficacy, which provides novel insight for future studies.

In conclusion, amniotic lacrimal duct stents may serve a therapeutic effect for dry eye, which has specific clinical value. However, the possible adverse reactions upon application require further investigation.

\section{Acknowledgements}

Not applicable.

\section{Funding}

The present study was supported by the National Natural Science Foundation of China (grant no. 81660158, 81460092 and 81400372); Natural Science Key Project of Jiangxi Province (grant no. 20161ACB21017); Youth Science Foundation of Jiangxi Province (grant no. 20151BAB215016,
20161BAB215198); Key Research Foundation of Jiangxi Province (grant no. 20151BBG70223 and 20181BBG70004); Education Department Key Project of Jiangxi Province (grant no. GJJ160020); Teaching Reform of Degree and Graduate Education Research Project of Jiangxi Province (grant no. JXYJG-2018-013); Grassroots Health Appropriate Technology 'Spark Promotion Plan' Project of Jiangxi Province (grant no. 20088003); Health Development Planning Commission Science Foundation of Jiangxi Province (grant no. 20175116); Health Development Planning Commission Science TCM Foundation of Jiangxi Province (grant no. 20150823).

\section{Availability of data and materials}

The analyzed data sets generated during the study are available from the corresponding author on reasonable request.

\section{Authors' contributions}

MM contributed to the study design, data collection, statistical analysis, data interpretation and manuscript preparation. QY contributed to the study design, data collection, statistical analysis and data interpretation. LY contributed to the statistical analysis and data interpretation. KL contributed to the manuscript preparation, literature search and funds collection. LHY contributed to the study design, data collection and funds collection. YM contributed to the literature search, statistical analysis and funds collection. NJ contributed to the literature search, statistical analysis and funds collection. QL contributed to the study design, statistical analysis and manuscript preparation. WS contributed to the literature search, statistical analysis and funds collection. XX contributed to the statistical analysis and data interpretation. PZ contributed to the study design, data collection and statistical analysis. YS contributed to the study design, data collection, statistical analysis, data interpretation, manuscript preparation and funds collection. All authors read and approved the final version of the manuscript.

\section{Ethics approval and consent to participate}

Ethics approval was obtained from the Medical Ethics Committee of The First Affiliated Hospital of Nanchang University.

\section{Patient consent for publication}

Not applicable.

\section{Competing interests}

The authors declare that they have no competing interests.

\section{References}

1. Cuevas M, González-García MJ, Castellanos E, Quispaya R Parra Pde L, Fernández I and Calonge M: Correlations among symptoms, signs, and clinical tests in evaporative-type dry eye disease caused by Meibomian gland dysfunction (MGD). Curr Eye Res 37: 855-863, 2012. 
2. Uchino Y, Uchino M, Dogru M, Ward S, Yokoi N and Tsubota K Changes in dry eye diagnostic status following implementation of revised Japanese dry eye diagnostic criteria. Jpn J Ophthalmol 56: 8-13, 2012.

3. The definition and classification of dry eye disease: Report of the definition and classification subcommittee of the international dry eye workshop (2007). Ocul Surf 5: 75-92, 2007.

4. The epidemiology of dry eye disease: Report of the epidemiology subcommittee of the international Dry Eye WorkShop (2007) Ocul Surf 5: 93-107, 2007.

5. Wenderlein M and Mattes S: The 'dry eye' phenomenon and ovarian function. Study of 700 women pre-and postmenopausal Zentralbl Gynakol 118: 643-649, 1996 (In German).

6. Gayton JL: Etiology, prevalence and treatment of dry eye disease. Clin Ophthalmol 3: 405-412, 2009.

7. Schaumberg DA, Sullivan DA, Buring JE and Dana MR: Prevalence of dry eye syndrome among US women. Am J Ophthalmol 136: 318-326, 2003.

8. John T and John OC: Ultrastructural characteristics of four types of human amniotic membranes. Invest Ophthalmol Vis Sci 42: 271-274, 2000

9. Mamede AC, Carvalho MJ, Abrantes AM, Laranjo M, Maia CJ and Botelho MF: Amniotic Membrane: From structure and functions to clinical applications. Cell Tissue Res 349: 477-458, 2012.

10. Lceffelbein DJ, Eaumann C, Stoeckelhuber M, Hasler R, Mücke T, Steinsträßer L, Drecoll E, Wolff KD and Kesting MR: Amniotic membrabe as part of a skin substitute for full-thickness wounds: An experimental evaluation in a porcine model. J Biomed Mater Res B Appl Biomater 100: 1245-1256, 2012.

11. Tseng SC, Espana EM, Kawakita T. Di Pascuale MA, Li W, He H, Liu TS, Cho TH, Gao YY, Yeh LK and Liu CY: How does amniotic membrane work? Ocul Surf 2: 177-187, 2004.

12. Shao Y, Zhou X, Yu Y, Pei CG, Zhou Q, Li J, Yang L, Dong WJ and Yi JL: Novel sutureless transplantation for primary pterygium associated with cysts. Int J Ophthalmol 4: 280-283, 2011.

13. Shao Y, Yu Y, Liu QP, Li JM, Dong F, Huang X, Pei CG, Tu P, $\mathrm{Li} \mathrm{HH}$ and Gao GP: Effects of Honghua preserved amnion membrane on scar healing in experimental glaucoma surgery. Int J Ophthalmol 7: 226-231, 2014.

14. Rauz S and Saw VP: Serum eye drops, amniotic membrane and limbal epithelial stem cells-tools in the treatment of ocular surface disease. Cell Tissue Bank 11: 13-27, 2010.

15. Tan Y, Qiu F, Qu YL, Li C, Shao Y, Xiao Q, Liu Z and Li W: Amniotic membrane inhibits squamous metaplasia of human conjunctival epithelium. Am J Physiol Cell Physiol 301: C115-C125, 2011.

16. Li LP, Kang HH, Ma MY, Ye L, Li QhH, Lan DY, Liu JX, Xu Qh, Yang YC, Yuan Q and Shao YI: Biological characteristics of ECM amniotic membrane rod and its application in rabbit dry eyes. Rec Adv Ophthalmol 38: 709-714, 2018.
17. Lemp MA: Report of the national eye institute/industry workshop on clinical trials in dry eyes. CLAO J 21: 221-232, 1995.

18. Pauly A, Brognole-baudouin F, Labbé A, Liang H, Warnet JM and Baudouin C: New tools for the evaluation of toxic ocular surface changes in the rat. Invest Ophthalmol Vis Sci 48: 5473-5483, 2007

19. Ang M, Sim DA, Keane PA, Sng CC, Egan CA, Tufail A and Wilkins MR: Optical coherence tomography angiography for anterior segment vasculature imaging. Ophthalmology 122: 1740-1747, 2015

20. Michelle H and Esen KA: Dry eye: An inflammatory ocular disease. J Ophthalmic Vis Res 9: 240-250, 2014.

21. Fayet B, Koster H, Benabderrazik S, Bernard JA and Pouliquen Y: Six canalicular stenoses after 34 punctal plugs. Eur J Ophthalmol 1: 154-155, 1991.

22. Javadi MA and Feizi S: Dry eye syndrome. J Ophthalmic Vis Res 6: 192-198, 2011.

23. Lemp MA: Management of dry eye disease. Am J Manag Care 14 (3 Suppl): S88-S101, 2008.

24. Management and therapy of dry eye disease: Report of the management and therapy subcommittee of the international dry eye worksho (2007). Ocul Surf 5: 163-178, 2007.

25. Allen CL, Clare G, Stewart EA, Branch MJ, McIntosh OD, Dadhwal M, Dua HS and Hopkinson A: Augmented dried versus cryopreserved amniotic membrane as an ocular surface dressing. PLoS One 8: e78441, 2013.

26. Alfawaz AM, Algehedan S, Jastaneiah SS, Al-Mansouri S, Mousa A and Al-Assiri A: Efficacy of punctal occlusion in management of dry eyes after laser in situ keratomileusis for myopia. Curr Eye Res 39: 257-262, 2014.

27. Yang QC, Bao J, Li C, Tan G, Wu AH, Ye L, Ye LH, Zhou Q and Shao Y: A murine model of dry eye induced by topical administration of erlotinib eye drops. Int J Mol Med 41: 1427-1436, 2018

28. Ang M, Cai Y, Shahipasand S, Sim DA, Keane PA, Sng CC, Egan CA, Tufail A and Wilkins MR: En face optical coherence tomography angiography for corneal neovascularization. Br J Ophthalmol 100: 616-621, 2016.

29. Ang M, Cai Y, MacPhee B, Sim DA, Keane PA, Sng CC, Egan CA, Tufail A, Larkin DF and Wilkins MR: Optical coherence tomography angiography and indocyanine green angiography for corneal vascularisation. Br J Ophthalmol 100: 1557-1563, 2016.

30. Lin H and Yiu SC: Dry eye disease: A review of diagnostic approaches and treatments. Saudi J Ophthalmol 28: 173-181, 2014.

31. Ljubimov AV and Saghizadeh M: Progress in corneal wound healing. Qrog Retin Eye Res 49: 17-45, 2015.

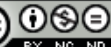

This work is licensed under a Creative Commons Attribution-NonCommercial-NoDerivatives 4.0 International (CC BY-NC-ND 4.0) License. 